No. 3951 July 21, 1945

mixtures containing salicylanilide give promise of protection upon the stems.

E. R. Speyer, studying the red-spider mite, finds that the application of top-dressings does not check infestation, and the use of petroleum emulsions provides the most practical control. The growth of wheat seedlings to act as bait for wireworm reduced their attack upon lettuce. $O$. Owen has investigated the interrelations of various nutrient elements for the tomato crop. Magnesium deficiency, for example, is related to nitrogen, and iron to manganese, while manganese and magnesium are possibly interdependent.

\section{STRUCTURE OF BIOLOGICAL FIBRES AND THE PROBLEM OF MUSCLE*}

TT is the mark of present-day biology that it looks ever more closely to "the Nature and Property of Local Motion" of the actual molecules of structures, and it is from such a point of view that the problem of muscle is again approached.

The physico-chemical mechanism of life is for the most part a manifestation of the forms and activities of chain-molecules, chief among which are the proteins, which include myosin, now generally accepted as the responsible contractile element of the muscle machine. X-ray studies show that myosin is a member of a family of fibrous proteins to which belong also the keratins of hair, etc., the fibrous proteins of the epidermis, and even fibrinogen and fibrin : all these are characterized by a similar molecular plan and by similar long-range elastic properties that rest on changes of form of the molecules themselves. The inference is that muscular activity is a special case of more general phenomena the full interpretation of which implies an understanding of the properties and significance of the keratin-myosin-fibrinogen group as a whole.

The isolated proteins of this group-and this holds too for the myosin in living muscle - oxist normally in a state in which the polypeptide chains are in a regularly folded configuration, but they may be pulled out into an extended configuration that is twice as long, and they may also be 'supercontracted' into more highly folded states. X-ray diffraction patterns of muscle, both living and dead, are throughout analogous to patterns that may be obtained from mammalian hairs, the 'supercontracted' state of the latter corresponding to the contracted state of the former. The outstanding common conclusion to be drawn from these photographs is that shortening is not a question of simple disorientation of fibrils, but rather of folding within fibrils.

Thermodynamic tests show that entropy changes play only a minor part in the elastic properties of keratin and isolated myosin, from which it is reasonable to suppose, especially in the light of the X-ray findings, that the various states of muscle itself are also based fundamentally on the potential energy associated with states of folding of the myosin chains. It now appears from recent physiological evidence that such a concept does indeed promise to coordinate quantitatively the energetics of living muscle.

* Substance of the Croonian Lecture delivered before the Royal Society by Dr. W. T. Astbury, F.R.S., on July 12.
A detailed solution of the muscle problem will be reached only as part of the detailed elucidation of protein structure, studied against the background of other macro-molecules, such as the nucleic acids and polysaccharides, with which protein activity is so intimately bound up. X-ray analysis is now boing supplemented by investigations with the electron microscope, and some of the evidence so obtained was presented.

\section{METER AND INSTRUMENT JEWELS AND PIVOTS}

TN order to obtain a more fundamental knowledge of the phenomena relating to meter and instrument bearings and to improve such bearings, research has been carried out for a number of years on behalf of the British Electrical and Allied Research Industries Association at the Meter Testing Laboratories of the Northmet Power Company. A paper read by G. F. Shotter before the Institution of Electrical Engineers in London on May 4 gives a brief survey of the various aspects covered by this research, dealing mainly with the sapphire/steel combination but including other combinations of materials.

The apparatus and methods of test are outlined, followed by a survey of the results from life-tests, including an analysis of the various factors which contribute to wear. The results of a microscopical examination of the units at the end of their life-run are discussed. A brief theory of the boundary lubrication existing in such bearings is given, with a short extract of the detailed discussion of the various factors contained in E.R.A. Reports.

The results of experiments on the resistance of sapphire jewels to impact forces are given; and the phenomena associated with bottom bearings at various loads, caused by parasitic forces existing in meters, are also dealt with. The actions of the balltype bearing and that of the pivot bearing are compared, and an approximate estimation of the life of bearings in practice, based on life-tests, is made.

A brief summary of the general conclusions reached during the tests is as follows. (a) Metals so far tried as alternatives to steel for pivots are in no way superior. The best material tested was osmiumrhodium, which gave good results in the dry as well as the lubricated condition. (b) With the exception of osmium-rhodium and possibly natural zircon $\left(90^{\circ}\right)$, the substitute materials tested, particularly glass, proved useless in the dry condition. (c) Various forms of oxide were produced, each having its own characteristics; one or two appeared to be selflubricating. (d) The initial friction of substitute materials was generally higher than that of the steel/ sapphire units. (e) With the exception of diamond, the substitute materials tested generally show a higher coefficient of friction than the steel/sapphire units. ( $f$ ) The range of penultimate/ultimate test values of friction shows considerable variation. Some materials, for example, natural zircon $\left(90^{\circ}\right)$, show a lower value than that of steel/sapphire. Other units, notably glass, give extremely high values, particularly in the dry condition. $(g)$ The type of wear area formed depends on the structure of the materials under test. Homogeneous and amorphous materials normally give circular wear. 